\title{
World wide wings
}

\section{Stuart Pimm joyously clicks his way through an ornithological classic as it goes online.}

$\mathrm{I}$ confess to knowing how many species of bird I have seen $(3,763)$ and that

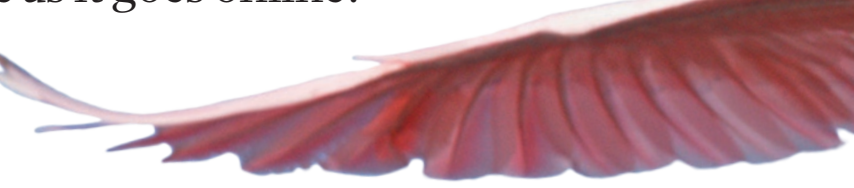

just over 200 people report having seen more. The eccentricity of ornithologists may be exceptional, but an interest in birds is not. Bird watchers are abundant (the Royal Society for the Protection of Birds is Britain's biggest nature-conservation charity) and ubiquitous (there are bird lists for the North and South Poles, and surely everywhere in between). So the combined knowledge of birdwatchers is prodigious. In the Handbook of the Birds of the World Alive (www.hbw.com), edited by a team led by Josep del Hoyo, that knowledge now has an online home, with a basic annual subscription available for $€ 29.95$ (US\$41).

The online handbook defines what we know about the biogeography, behaviour and ecology of the almost 10,000 extant avian species at a time of unprecedented environmental change. It allows the compilation of instant, custom-made field guides. Its facility for species comparisons will accelerate comparative studies, and embedded user-supplied data will open up new research opportunities.

The first volume of Handbook of the Birds of the World was published in 1992 by Lynx Edicions of Barcelona, Spain. Some 15 million words, 1,000 colour plates and 100,000 references later, the seventeenth and
Handbook of the Birds of the World Alive EDITED BY JOSEP DEL HOYO ET AL. Lynx: 2013. final volume arrived this year. These gorgeous books carry the limitations of print, of course - for instance, they demand the tedious perusal of indexes to find information, and provide no easy connection to the materials quoted.

The online version makes obvious questions easy. So, for 'what?' I click on a thumbnail of gulls and get a plate, scaled by size, of the 51 species. For 'where?' I filter the search by Chile and Argentina and find 14 species I might see on an upcoming trip. I could have added terns, other bird families or other countries. The 'compare' feature stacks similar species, such as Belcher's and Olrog's gulls, side by side. The taxonomy section tells me that taxonomists once considered these two birds to be the same species. Maps show that the former lives on Pacific coasts and the latter on Atlantic ones; text compares descriptions, habitats and natural history.

The International Union for Conservation of Nature's Red List gives Olrog's gull 'vulnerable' status. Using an embedded link, I access the curated Internet Bird Collection: 9,312 bird species feature in a collection that includes almost 100,000 photos and 80,000 videos. Ten of the items for Olrog's gull are connected to a Google Earth map. I shall soon sail past one of these locations. The prospect of a sighting is unreasonably exciting.

For many species, the best way to find and identify birds is through their call, so I click the link for Xeno-canto, the online database of bird calls and songs. It provides both a recording and a sonogram. Another

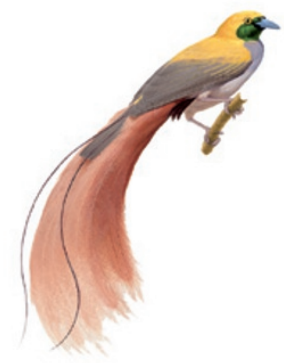

4. Goldie's Bird-of-paradise (Paradisaea decora)

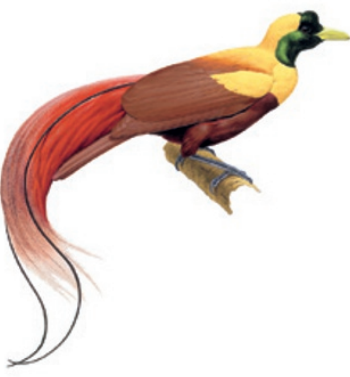

5. Red Bird-of-paradise (Paradisaea rubra) o

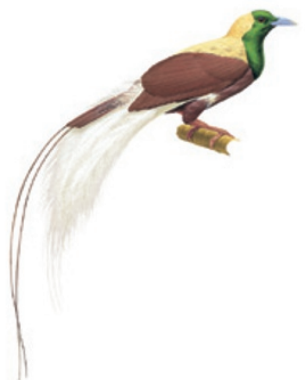

6. Emperor Bird-of-paradise (Paradisaea guilielmi) $\hat{\sigma}$
The online Handbook of the Birds of the World Alive allows a comparison of similar species.
A roseate spoonbill (Plateala ajaja) soars through the sky in Florida, USA.

link takes me, via Cornell University's Lab of Ornithology, to eBird - a massive, global, crowd-sourced compilation of observations. A link to BirdLife International tells me why Olrog's gull is threatened. Active links to original sources are included, too. I can add my comments online and point to egregious failures to quote every last one of my published bird papers, however obscure. And Google's translation technology means that the whole resource can be read in 71 languages.

The march of online and crowd-sourced data is changing research completely and goes far beyond birds. For example, through smartphone apps such as iNaturalist, amateurs and professionals alike are sharing information on the species they are passionate about - be they frogs, seahorses or wild pigs - from Aiguabarreig Segre-Cinca in Catalonia, Spain, to Xishuangbanna in Yunnan, China. Through these, we are rapidly learning precisely where species are and so can quickly pinpoint where habitat loss and climate disruption may move them and where extinctions happen.

The handbook's users can check off the species they have seen in their lifetime. Sightings are reported for 14 of the 20 species that have recently become extinct or extinct in the wild, meaning that extinctions are current, not historical, events. The handbook lists 176 species as 'critically endangered'. When, and how often, birders last counted these provides the grist for the statistical mill that predicts how likely it is that a species still survives, and so can be saved (see S. Pimm Nature 426, 235-236; 2003). Out of eccentricity comes insight and, perhaps, even conservation action.

Stuart Pimm is professor of conservation at the Nicholas School of the Environment, Duke University, Durham, North Carolina, USA, and author of The World According to Pimm: A Scientist Audits the Earth. e-mail:stuartpimm@me.com 